\title{
Gestão da água e saneamento básico: reflexões sobre a participação social
}

\author{
Water resources management and basic sanitation: \\ reflections on social participation
}

\section{Cezarina Maria Nobre Souza}

Instituto Federal de Educação, Ciência e Tecnologia do Pará, Belém, PA, Brasil.

E-mail: cezarina.souzaœoi.com.br

\section{Correspondência}

Av. Almirante Barroso, 1.155, bloco N, Coordenação de Saneamento. Belém, PA, Brasil. CEP 66093-020.

\section{Resumo}

Tendo como objeto a participação social na gestão dos recursos hídricos no Brasil, este trabalho, ao analisar o texto da política nacional (Lei $\mathrm{n}^{0}$ 9.433/1997) e a produção científica correlata, pretende contribuir para o aperfeiçoamento da governança desses recursos no país. Tal proposição é relevante em si mesma, haja vista o destaque dado pela literatura científica à gestão participativa da água, ainda mais em um contexto de escassez, como o que persiste em algumas regiões brasileiras. Além disso, as contribuições pretendidas também poderão ser úteis para a área de saneamento básico, ainda neófita no exercício dessas práticas e com quem os recursos hídricos estão intimamente associados. A análise revelou a importância das disposições legais existentes, que determinam a participação como princípio orientador das práticas exercidas. Indicou, também, fatores cuja atuação redunda em uma participação assimétrica, limitada, excludente ou até mesmo nula. Concluiu-se que, para superar tais fatores em prol da efetividade do controle social, a ampla capacitação dos agentes sociais constitui ação necessária.

Palavras-chave: Controle Social; Saneamento; Recursos Hídricos. 


\section{Abstract}

Considering social participation in water management in Brazil as its subject and analyzing the Brazilian national policy (Law no. 9,433/1997) and the related scientific literature, this article intends to contribute to the improvement of governance practices of this natural resource in the country. This proposition is relevant in itself, considering the emphasis in the scientific literature on participatory water management, especially in a context of scarcity, such as the one persisting in some Brazilian regions. In addition, the intended contributions may also be useful for basic sanitation, still new to the exercise of these practices and with which water resources are intimately associated. The analysis revealed the importance of existing legal provisions, which determine participation as a guiding principle of the practices. It also indicated factors which redounds in an asymmetrical, limited, excluding, or even non-existing participation. In conclusion, the broad training of social agents is an action necessary to overcome such factors in favor of social control effectiveness.

Keywords: Social Control; Sanitation; Water Resources.

\section{Introdução}

Os eventos de escassez hídrica no século XXI vêm sendo apontados como consequência de fatores diversos: falhas no processo de gerenciamento do recurso, sem que haja, de fato, escassez; problemas ambientais agravados por outros problemas ligados ao contexto econômico e social; reais problemas de disponibilidade e aumento da demanda, aliados a um processo não sistêmico e preditivo de gestão, voltado apenas para ações setoriais e de resposta a crises (Tundisi, 2008). Contudo, há autores que destacam a governança como o principal fator envolvido (Castro, 2007).

Analisando especificamente a gestão da água, alguns pesquisadores (Malheiros; Prota; Rincón, 2013) asseveram que esta vem sendo uma preocupação presente em todos os eventos internacionais desde a Conferência das Nações Unidas sobre o Meio Ambiente, ocorrida em Estocolmo, na Suécia, em 1972. De acordo com esses autores, a partir da Conferência das Nações Unidas sobre a Água, realizada em Mar del Plata, na Argentina, em 1977, vem sendo destacada a importância de uma maior atenção ao planejamento integrado do uso desse recurso, associado a medidas que assegurem a participação efetiva de usuários e autoridades públicas no processo de planejamento e tomada de decisões.

Segundo a Comissão Econômica para América Latina e o Caribe (Cepal), o destaque à participação pública se acentuou na Conferência Internacional sobre a Água e o Meio Ambiente, realizada em Dublin, na Irlanda, em 1992, sendo a participação alçada à condição de um dos quatro princípios básicos para a gestão da água. Conforme o documento produzido na conferência, o aproveitamento e a gestão do recurso hídrico devem se caracterizar pela participação dos usuários, dos planejadores e dos responsáveis pelas decisões em todos os níveis (Cepal, 1998).

No Brasil, sob a influência desses eventos e do movimento ambientalista, a Constituição Federal de 1988, em seu art. 21, inciso XIX (Brasil, 1988), determina que cabe à União instituir o sistema nacional de gerenciamento de recursos hídricos, o que foi regulamentado, em 1997, pela Lei nº 9.433 (Brasil, 1997). Tal lei, ao instituir a Política Nacional 
de Recursos Hídricos (PNRH), o faz considerando ser a água um bem público que deve ser gerido por meio de uma política descentralizada que conte com a participação do poder público, dos usuários e das comunidades.

Além disso, em 2006, antecipando-se à Resolução A/RES/62/292 da Organização das Nações Unidas (ONU, 2010), o Brasil, por meio da Lei n ${ }^{0} 11.346$ (Brasil, 2006), institui o Sistema Nacional de Segurança Alimentar e Nutricional, reconhecendo o acesso à água como um direito fundamental, inerente à dignidade do ser humano e indispensável à realização dos demais direitos constitucionais.

Diante da ênfase à participação na gestão de algo que constitui um direito humano fundamental, e considerando o momento atual, marcado pela escassez de água em algumas regiões do país (Nogueira, 2016; Pimentel, 2016), é relevante discutir essa experiência participativa. Algumas questões se destacam: o que caracteriza o viés participativo da PNRH? Quais os motivos de interesse/desinteresse dos atores sociais pela participação em fóruns de gestão da água? Qual a representatividade dos usuários e da chamada "sociedade civil” nesses fóruns participativos? Quais as condições para deliberação livre e consciente por parte dos participantes desses fóruns? Como se dá o controle dos representantes que participam dos fóruns pelos representados que os indicaram? Qual a influência externa das tomadas de decisão nos fóruns?

Responder a essas perguntas-problemas constitui o objetivo deste trabalho, com vistas a contribuir para o aperfeiçoamento das práticas participativas de gestão das águas, o que é relevante em si mesmo.

Além disso, a relevância do trabalho também se evidencia pela contribuição que poderá dele advir para a área de saneamento básico e saúde ambiental, por três razões: (1) o saneamento tem ampla interface com a gestão hídrica, considerando-se, por exemplo, a captação de água para tratamento e distribuição para o abastecimento público e o lançamento de esgotos em corpos hídricos receptores, o que afeta a saúde pública e ambiental, requerendo uma visão estratégica participativa e intersetorial; (2) data apenas de 2007 a instituição legal de instrumentos participativos na área, o que representa ainda uma novidade para gestores e usuários, que poderão se beneficiar da experiência da gestão das águas; (3) têm sido identificadas dificuldades para colocar em prática os instrumentos legais participativos (Mello; Rezende, 2014; Piterman; Heller; Rezende, 2013).

Na seção seguinte, são apresentadas breves considerações conceituais sobre controle social e, na sequência, estão a metodologia empregada para o alcance do objetivo proposto, os resultados obtidos e sua discussão e as considerações finais.

\section{Participação: o controle social}

No Brasil, por ocasião do último processo constituinte (1986-1988), destacou-se a necessidade da participação social, o que foi incorporado como diretriz de diversas políticas, dentre as quais a de recursos hídricos, na perspectiva do controle social.

O termo "controle social" pode ser entendido no eixo da relação Estado-sociedade civil a partir do aparato teórico proposto por Antonio Gramsci (Correia, 2005). Há que se considerar, também, em relação à proposição gramsciana, a distorção que sofreu o conceito de sociedade civil no Brasil (Coutinho, 200o), com reflexos sobre o conceito de controle social (Bravo; Correia, 2012).

Segundo a concepção gramsciana, Estado e sociedade civil não se opõem entre si, pois constituem uma unidade orgânica; a sociedade civil é perpassada pela luta de interesses antagônicos entre as classes que nela interagem - as que dominam e as subalternas -, sendo estas entendidas como as que estão fora do poder e ocupam lugar de menor importância nas relações de produção; o Estado representa os interesses da classe dominante, mas incorpora demandas das classes subalternas (Correia, 2005).

Gramsci compreende o Estado de forma ampliada, como totalidade social, em conjunto com a sociedade civil. Como um momento do Estado, está o Estado stricto sensu ou restrito, também chamado sociedade política ou Estado-coerção, pois é onde se concentra o poder político e a força, exercidos por meio de aparelhos de coerção controlados pela burocracia executiva e policial-militar (Coutinho, 2001).

A sociedade civil, para Gramsci, como parte da totalidade social, encerra um conjunto de aparelhos privados de hegemonia (escolas, igrejas, sindicatos, 
meios de comunicação). É um espaço no qual se dá a formação, não do poder político, mas ideológico: os valores e normas de uma classe social se tornam hegemônicos sobre as demais classes, não pela força, mas pela cultura produzida e difundida por meio dos citados aparelhos e incorporada e assumida pelas classes subalternas (Carnoy, 1988; Macciocchi, 1980).

Em outras palavras, a sociedade civil, para Gramsci, é um espaço no qual estão representados interesses classistas - diferentes, não homogêneos e antagônicos - que fomentam as ideologias que nele circulam (Bravo; Correia, 2012). Estas, difundidas no sentido de influenciar o aparelho estatal, interferem no modo de vida dos indivíduos, reforçando a internalização de normas e comportamentos que passam a ser legitimados socialmente com o fim exclusivo de assegurar a reprodução do capital (Iamamoto; Carvalho, 1988).

Relativamente à participação e ao controle social, atendendo aos interesses das classes dominantes de minimizar a influência das subalternas, podem ser citados como exemplo alguns mitos ideológicos: (1) a participação não muda por si só a realidade (ideia que despolitiza a participação ao desconsiderar a existência de indivíduos contrários às mudanças e a correlação de forças, que se organiza em torno de interesses diversos); (2) a sociedade não está preparada para participar como protagonista das políticas públicas (justifica a tutela do Estado sobre a sociedade civil); (3) a sociedade não pode compartilhar da governabilidade (restringe a participação ao momento da eleição, sem que caiba aos eleitores qualquer possibilidade de interferência nas ações do governo eleito (Moroni, 2009).

Como lócus do poder, o Estado stricto sensu, dominado pelos interesses hegemônicos na sociedade civil, assume o papel de mantenedor do consenso e da hegemonia da classe dominante sobre as classes subalternas. Para isso, incorpora demandas destas e promove concessões, com o fito de obter seu “consentimento ativo” em relação às determinações dominantes. Segundo Carnoy (1988), trata-se de uma ação dinâmica, que tem por fim se acomodar constantemente às circunstâncias históricas e às demandas humanas.
Com base no exposto, o controle social pode ser entendido como o controle das ações do Estado por segmentos atuantes na sociedade civil. Estes disputam entre si para alcançar a hegemonia e, consequentemente, o controle do Estado. Sendo assim, do ponto de vista das classes subalternas, o controle decorre de sua atuação organizada para produzir consensos em torno de seus interesses, para, então, atuar com o fim de assegurar que as políticas públicas atendam sempre - e cada vez mais a esses interesses e demandas (Correia, 2005).

Para tanto, há que se levar em conta que atuar em espaço tão contraditório requer que as classes subalternas não se deixem cooptar e não pactuem consensos em torno de mudanças de políticas públicas que estejam voltadas para a expansão do capital, em forma de redução de gastos sociais e privatizações de serviços essenciais.

Como discutido, para Gramsci, a sociedade civil é um espaço, uma arena de disputas, e não um ente social ou um bloco monolítico dentro do qual não há interesses contraditórios. Contudo, no Brasil, segundo Coutinho (200o), tal conceito foi equivocadamente identificado com o que entrou em voga no contexto da luta contra a ditadura militar, na segunda metade dos anos 1970, e que se tornou sinônimo de oposição ao Estado ditatorial. Surgiu daí uma dicotomia - Estado versus sociedade civil - que em Gramsci não ocorre, marcada também por um tom maniqueísta, posto que tudo o que provinha da sociedade civil era considerado de forma positiva, enquanto tudo o que dizia respeito ao Estado era visto negativamente.

Essa dicotomia maniqueísta, a partir do final dos anos 1980, ainda segundo Coutinho (2000), foi apropriada por parte das então ascendentes ideias neoliberais, de forma que o Estado passou a ser ainda mais demonizado, e a sociedade civil, vista como um ente homogêneo e despolitizado.

No contexto deste estudo, ao observar-se a composição das instâncias de controle social, constata-se a existência de um segmento denominado “sociedade civil". Nesse caso, parece ter-se um terceiro sentido para o termo, que representa não uma totalidade social em conjunto com o Estado stricto sensu, como em Gramsci, ou um ente único e homogêneo, conforme analisa Coutinho (200o), 
mas um grupo dentro do qual estão, por exemplo, associações científicas, associações técnicas, organizações sindicais, usuários da água para comércio, lazer e serviços, usuários agrícolas, usuários industriais e usuários para abastecimento público, cada um com seus interesses próprios.

Em atenção à recomendação de Bravo e Correia (2012) sobre a importância de ter-se claro entendimento do significado dos termos em tela, é relevante levar em conta de que sociedade civil está se falando neste estudo, especificamente quanto à análise da representatividade dos membros das instâncias de controle social.

\section{Metodologia}

Com o objetivo de obter uma resposta para a primeira pergunta-problema proposta nesta investigação - "o que caracteriza o viés participativo da PNRH?" -, foi realizado estudo da Lei nº 9.433/1997 com base nos seguintes critérios: (1) contexto em que a participação é apresentada; (2) instâncias participativas estabelecidas; (3) participantes das instâncias participativas; (4) competências das instâncias participativas.

No que tange às demais perguntas-problemas, foi realizada revisão da literatura científica nacional com vistas a identificar estudos acerca da participação social na gestão das águas a partir da PNRH.

O universo de busca foi composto pela base de dados de livre acesso Scientific Electronic Library (SciELO) e pela base de dados de dois periódicos especializados em recursos hídricos, ambos publicados pela Associação Brasileira de Recursos Hídricos (ABRH): a Revista Brasileira de Recursos Hídricos (RBRH) e a Revista de Gestão da Água na América Latina (Rega). Foram empregadas, em diversas combinações, as palavras-chave: recursos hídricos, participação, água, bacia, gestão das águas, comitês de bacia hidrográfica, comitês de bacias, gestão de recursos hídricos.

A busca, realizada em julho de 2015, possibilitou a identificação de 75 artigos. Excluindo-se as duplicidades e também os artigos que não ofereceram resposta às perguntas-problemas, foram analisados 18 textos.

\section{Resultados}

\section{Participação na Política Nacional de Recursos Hídricos}

Respondendo à pergunta "O que caracteriza o viés participativo da PNRH?”, em relação ao primeiro critério (contexto em que a participação é apresentada), observa-se que a palavra "participação" é recorrente no texto da Lei ${ }^{\circ}$ 9.433. Logo em seu art. $1^{\circ}$, está estabelecido que "a gestão dos recursos hídricos deve ocorrer de forma descentralizada e contar com a participação do Poder Público, dos usuários e das comunidades" (Brasil, 1997).

Tomando como referencial o segundo critério (instâncias participativas estabelecidas), observase que o art. 33, com redação dada pela Lei $n^{0}$ 9.984/200o, indica as instâncias que integram o Sistema Nacional de Gerenciamento de Recursos Hídricos (Singreh), cuja função é, segundo o art. 32, inciso I, coordenar a gestão integrada dos recursos hídricos. São elas: o Conselho Nacional de Recursos Hídricos (CNRH); a Agência Nacional de Águas (ANA); os conselhos de recursos hídricos dos estados e do Distrito Federal (CERH); os comitês de bacia hidrográfica (CBH); os órgãos do poder público federal, estadual, municipal e do Distrito Federal cujas competências se relacionam com a gestão de recursos hídricos e as agências de água. Dentre esses componentes, conclui-se que o CNRH, os CERH e os CBH são as instâncias que possibilitam o controle social das tomadas de decisão.

Tendo o terceiro critério (participantes das instâncias participativas) como referência, segundo o art. 34, o CNRH deve ser composto por representantes dos ministérios e secretarias com atuação na gestão ou uso da água, dos CERH e dos usuários e de organizações dos recursos hídricos, tendo como presidente o ministro do Meio Ambiente. Observa-se, ainda, que o número de representantes do executivo federal não pode ultrapassar a metade mais um do total de membros.

Os CBH, segundo o art. 39, são compostos por: representantes da União, dos estados e do Distrito Federal cujos territórios se situem, ainda que parcialmente, em suas respectivas áreas de atuação; municípios situados no todo ou em parte em sua 
área de atuação; usuários das águas de sua área de atuação e entidades civis de recursos hídricos com atuação comprovada na bacia. Note-se que o número de representantes da União, estados e municípios fica limitado à metade do total de membros do comitê.

Segundo o art. 47, somente são consideradas organizações civis dos recursos hídricos: os consórcios e associações intermunicipais de bacias hidrográficas; as associações regionais, locais ou setoriais de usuários de recursos hídricos; as organizações técnicas e de ensino e pesquisa com interesse na área de recursos hídricos; as organizações não governamentais com objetivos de defesa de interesses difusos e coletivos da sociedade e as outras organizações reconhecidas pelo $\mathrm{CNRH}$ ou pelos CERH.

Relativamente ao quarto critério (competências das instâncias participativas), pelo conjunto de competências estabelecidas pelo art. 35 para o $\mathrm{CNRH}$ e pelo art. 38 para os CBH, observa-se que o caráter dessas instâncias é deliberativo. Tais competências, no caso do CNRH, se reportam a, por exemplo, articular o planejamento de recursos hídricos com o planejamento nacional, regional, estadual e dos setores usuários; arbitrar, em última instância administrativa, os conflitos existentes entre CERH e deliberar sobre os projetos de aproveitamento de recursos hídricos cujas repercussões extrapolem o âmbito dos estados em que serão implantados.

No que diz respeito aos $\mathrm{CBH}$, consistem em promover o debate das questões relacionadas a recursos hídricos arbitrando conflitos em primeira instância administrativa, bem como acompanhando a execução do plano de recursos hídricos da bacia e sugerindo providências necessárias ao cumprimento de suas metas.

\section{Participação no universo das práticas exercidas em torno da Política Nacional de Recursos Hídricos}

Relativamente à pergunta "O que caracteriza o viés participativo da PNRH?”, embora a proposta metodológica tenha sido respondê-la com base na análise da própria política, como exposto na seção "Metodologia", durante a revisão da literatura foram identificados diversos textos que, com maior ou menor ênfase, de forma direta ou indireta, afirmam esse viés, ratificando o exposto na seção anterior (Figueirêdo et al., 2008; Haase; Gutiérrez, 2008; Jacobi; Barbi, 2007; Padilla et al., 2013; Santin; Goellner, 2013; Tundisi, 2008; Vieira, 2002; Wolkmer; Pimmel, 2013).

A respeito da pergunta "Quais os motivos de interesse/desinteresse dos atores sociais pela participação em fóruns de gestão da água?", os textos consultados revelam fatores que podem influenciar de perto tal interesse/desinteresse, tais como a cultura política e o capital social (Campos, 2005) - este concebido como conjunto de elementos de organização da vida social, tais como redes, normas e confiança social, que facilitam a ação conjunta em prol de objetivos comuns (Putnam, 2002) e aquela entendida como o conjunto de atitudes, normas e crenças mais ou menos partilhadas pelos membros de uma comunidade (Bobbio, 1986).

Há relatos de que o interesse pela água para fins comerciais (distribuição pública, uso em processos produtivos, meio de transporte e lazer) e para uso como elemento vital (alimentação, higiene e lazer) por parte de ribeirinhos constitui o móvel da participação para diversos atores sociais (Flores; Mizoczky, 2008). Além disso, também é destacado o interesse em obter financiamentos advindos de fundos públicos, viabilizados pela participação em comitês de bacia (Malheiros; Prota; Rincón, 2013), bem como em assegurar recursos derivados do pagamento financeiro por serviços de proteção ambiental nas propriedades rurais (proteção de nascentes, por exemplo) (Chiodi; Sarcinelle; Uezu, 2013).

Um raro estudo sobre o desinteresse de organizações da sociedade pela participação em comitês de bacia esclarece que tal fato nem sempre resulta de regras excludentes, e que pode, mesmo, refletir as estratégias utilizadas por essas organizações com o fito de influenciar o Estado de forma diferente (Empinotti, 2011).

Igualmente, tornam-se empecilhos à participação fatores como a falta de recursos financeiros para viabilizar o deslocamento dos membros para as reuniões e para cobrir outros custos materiais (inclusive de alimentação), a dificuldade para uso do carro da entidade participativa, a demora do ressarcimento de despesas e a não liberação do 
trabalho profissional (Araújo; Ribeiro; Vieira, 2012; Empinotti, 2011; Malheiros; Prota; Rincón, 2013).

Relativamente às divergências que paralisam as ações dos fóruns nas tomadas de decisão, como proposta para lidar com elas e alavancar o processo participativo, é destacada a importância do diálogo entre governo, técnicos e usuários da água (Jacobi; Barbi, 2007; Porto; Porto, 2008).

Acerca da pergunta "Qual a representatividade dos usuários e da chamada sociedade civil nos fóruns participativos?", para alguns autores, há no Singreh, em todas as suas instâncias e plenários, desde o Conselho Nacional de Recursos Hídricos até os comitês de bacia hidrográfica, a garantia de participação dos usuários e da sociedade civil (Porto; Porto, 2008).

Entretanto, há um estudo (Abers et al., 2009), desenvolvido em comitês de bacia das regiões nordeste, sudeste e sul, que relativiza esse fato. Esse estudo, apesar de revelar a existência, nesses espaços, de percentual de assentos maior que o esperado para a sociedade civil e usuários de pequeno porte em detrimento de grandes e médios usuários, faz importante ressalva. Os autores destacam a necessidade de observar, por um lado, que a categoria sociedade civil é bastante variada, incluindo desde universidades e associações técnicas até associações de moradores. Por outro lado, também chamam atenção para estudos qualitativos aprofundados, reveladores de que, mesmo na ausência de maioria na representação, as elites mantêm seu predomínio por meio de uma rede de negociações.

Além disso, há os chamados conflitos organizacionais (Araújo; Ribeiro; Vieira, 2012), como, por exemplo, haver representantes do poder público constando como usuários de água, ou usuários integrados como sociedade civil. Há estudos (Araújo; Ribeiro; Vieira, 2012; Uller-Gómez; Sheibe; Reis, 2008) que afirmam ser este problema causado pela imprecisa definição das categorias pela legislação nacional. A consequência, segundo eles, é a fragilização das tomadas de decisões, visto que, por vezes, os membros de dado segmento defendem interesses opostos aos da categoria em que se enquadram.

No que tange à pergunta "Quais as condições para deliberação livre e consciente por parte dos participantes nos fóruns participativos?", os textos consultados indicam que atores mais organizados e detentores de recursos políticos (riqueza, dinheiro, educação, recursos cognitivos, tempo livre para a atividade política, facilidade maior de superar problemas de ação) (Campos, 2005) ou econômicos e sociais e de informação (Jacobi; Barbi, 2007), tornam-se privilegiados no acesso à participação nos processos decisórios.

Como consequência, ocorre a exclusão participativa (Empinotti, 2011), designação dada ao controle das discussões, nos fóruns participativos, por parte de atores privilegiados. Em outras palavras, os grupos que não dominam os códigos de uma linguagem técnica, por exemplo, apesar de estarem presentes, permanecem excluídos das discussões e tomadas de decisão.

Um estudo baseado em revisão da literatura científica (Martins, 2015) investiga as diferenças entre membros participantes do processo de gestão das águas e as desigualdades que se configuram a partir delas, dentre as quais está a de conhecimento técnico. Para o autor, nos comitês de bacia brasileiros há uma passagem da diferença para a desigualdade, como resultante de um processo de naturalização da competência perita sobre os saberes leigos, com grande desvalorização destes, inclusive por meio de práticas de estigmatização. A relação que se estabelece entre peritos e não peritos se afasta da diferença entre pontos de vista, salutar para a governança ambiental, e passa a se configurar como desigualdade.

Outros estudiosos (Abers et al., 2009) observam em seu trabalho que seus entrevistados julgam os danos à decisão democrática, decorrentes da distribuição desigual de conhecimento técnico, maiores do que os resultantes de outros tipos de desigualdade, como as desigualdades econômicas e de poder político. Sobre este último, há destaque para a atuação do Poder Executivo em geral, muitas vezes capaz de manobrar e manipular em favor de seus interesses (Jacobi; Barbi, 2007) e, de forma mais específica, do Poder Executivo Federal, que foi capaz de aprovar o projeto de transposição do Rio São Francisco no Conselho Nacional de Recursos Hídricos sem observar as recomendações do comitê da bacia hidrográfica local (Empinotti, 2011). 
Relativamente à pergunta "Como se dá o controle dos representantes participantes dos fóruns pelos representados que os indicaram?", há relatos de que membros de um comitê de bacia, após sua eleição, deixavam de interagir com as organizações que os elegeram, passando a tomar decisões por conta própria, de modo que essas bases não conseguiam influenciá-los e tampouco levar suas demandas para a negociação (Empinotti, 2011).

Um estudo (Abers et al., 2009) informa que há registros de casos em que, mesmo provindo de bases atuantes e prestando contas a elas, a maioria dos representantes toma decisões por conta própria. Para seus autores, a partir desse achado, fica evidenciado o equívoco dos estudiosos que, frequentemente, atribuem a ausência de prestação de contas à existência de bases pouco organizadas.

No que diz respeito à pergunta "Qual a influência externa das tomadas de decisão nos fóruns?", considerando o Estado, o setor privado e a sociedade em geral, um estudo revela que a maior influência se dá sobre o Estado, ou seja, sobre as políticas por ele propostas, ficando em segundo plano os outros dois setores (Abers et al., 2009).

Os autores da pesquisa, contudo, ressaltam que essa análise é limitada, uma vez que não dispõem de dados comparativos globais acerca da implementação de decisões tomadas pelos comitês e consórcios de bacias hidrográficas, além de não estar claramente evidenciado que tal comparação seja possível, dada a grande variedade de tipos de decisão que esses organismos tomam nos seus processos decisórios. Portanto, seus dados baseiamse somente na percepção de entrevistados (membros de comitês e consórcios) sobre a sua capacidade/ habilidade de influenciar o Estado, os usuários de água e a população em geral.

\section{Discussão}

Um dos requisitos da gestão integrada dos recursos hídricos (GIRH), lançada pela Associação Mundial de Água em 2000, é a organização da comunidade para participar da gestão da bacia hidrográfica (Padilla et al., 2013). Atualmente, tal requisito, sob diferentes conformações, está presente na legislação de países como Venezuela,
Peru e Bolívia (Dourado Junior, 2011), assim como nos Estados Unidos e Colômbia, ainda que neste último de maneira informal (Padilla et al., 2013).

$O$ viés participativo da PNRH é identificado pela existência recorrente, em seu texto, de inúmeros artigos que determinam a participação pública nos fóruns de gestão das águas, como característica dos procedimentos de gestão, juntamente com a descentralização. Esse viés se expressa também pela definição de três instâncias participativas, o $\mathrm{CNRH}$, os CERH e os CBH, fóruns que contam com a participação de representantes da União e de estados e municípios localizados na bacia hidrográfica, além de usuários e entidades civis. Além disso, tais instâncias têm caráter deliberativo, evidenciado por suas competências, designadas pelos verbos arbitrar e deliberar, por exemplo.

Essa característica participativa, inspirada na seminal experiência francesa (Prota, 2011), que, inclusive, é bem anterior à proposta de GIRH, não incorporou, contudo, a criação de instâncias locais, designadas na França como comissões locais de água (Braga; Ferrão, 2015). Tais comissões, compostas por representantes das coletividades, dos usuários (industriais, agricultores, associações de proteção ambiental etc.) e do Estado (Berreta; Laurent; Basso, 2012), atuam nos comitês de bacia e possibilitam o envolvimento dos municípios na gestão, em nível de sub-bacia, principalmente quando se trata de processos decisórios que envolvem mais de um município.

Conforme argumentam alguns estudiosos (Braga; Ferrão, 2015), os municípios têm pouco envolvimento na gestão das águas, uma vez que, pela legislação, somente são exigidos planos de recursos hídricos em escala nacional, estadual e da bacia hidrográfica, sendo insuficientes as abordagens feita nos planos diretores municipais, posto que estas, em geral, são direcionadas a aspectos relacionados ao uso e à ocupação do solo.

Nesse sentido, não é somente no Brasil que a falta de uma gestão local tem sido questionada. 0 recente processo de discussão da Lei das Águas, no Equador, por exemplo, foi marcado por reivindicações e protestos de comunidades indígenas em favor da chamada gestão comunitária, atendendo a demandas sociais e mesmo espirituais dessas comunidades (Iela, 2015). 
Os motivos de interesse pela participação são diversos, desde comerciais e de acesso a recursos públicos até ligados à própria manutenção da vida. Os empecilhos a essa participação, por outro lado, além de materiais, são de natureza burocrática. Chama atenção, pela sua procedência, a referência ao capital social e à cultura política como mediadores desse processo, mas também é relevante lembrar a influência das ideologias que desqualificam a participação e reforçam a internalização de normas e comportamentos que passam a ser legitimados socialmente, com o fim exclusivo de assegurar a reprodução do capital (Iamamoto; Carvalho, 1988; Macciocchi, 1980; Moroni, 2009).

Nos fóruns, a sociedade civil é assinalada como um grupo composto por membros de diversas procedências/entidades, conforme já discutido. Sobre sua representatividade, observa-se que, mesmo estando em maior número que os demais segmentos, não se pode afirmar ser efetiva a representação dos mais excluídos sem conhecer e examinar de perto, caso a caso, cada uma dessas instâncias.

As evidências do predomínio das elites nos fóruns das águas, mesmo na ausência de representação majoritária, ilustra os mecanismos ideológicos por elas movimentados para assegurar a manutenção do status quo que lhes beneficia os interesses (Correia, 2005; Iamamoto; Carvalho, 1988; Moroni, 2009). Ilustra também, claramente, a concepção de Gramsci de que a sociedade civil é perpassada por interesses diversos e antagônicos que disputam entre si o controle das ações do Estado. Reconhecer isto é essencial para que se possa pensar na efetividade do controle social por parte dos setores sociais mais excluídos.

Relativamente às condições para deliberação livre e consciente por parte dos membros dos fóruns, os autores consultados convergem para a identificação de limites à participação, que giram em torno, por exemplo, da valorização do conhecimento técnico, que setores da sociedade civil, como os usuários, em geral não possuem.

Tal circunstância, que a princípio constitui apenas uma diferença entre os diversos atores nos fóruns, alcança patamares relevantes e prejudiciais ao processo deliberativo livre e consciente, pois configura desigualdade entre os participantes, mais significativa que a desigualdade decorrente do poder econômico e político. É a exclusão participativa, que se dá até por meio da estigmatização, na medida em que uns dominam os códigos de linguagem que lhes franqueiam maior capacidade de argumentação livre e consciente, enquanto outros são tolhidos por não lograrem expressar-se nessa linguagem, sendo desvalorizados por serem detentores de conhecimentos empíricos e saber popular.

Analisando esse fato a partir do referencial teórico apresentado (Carnoy, 1988; Correia, 2005; Iamamoto; Carvalho, 1988), observa-se a "concessão" de participação aos segmentos subalternos, incorporando algumas de suas demandas, ao mesmo tempo em que se evidencia a movimentação, pelas elites, de mecanismos que obstaculizam o acesso à educação e ao conhecimento, produzindo condições propícias à manutenção do status quo que assegura seus interesses e demandas em detrimento dos interesses coletivos.

Relativamente ao controle dos representantes pelos representados que os indicaram e à prestação de contas às bases, fica patente, principalmente em um dos trabalhos citados (Abers et al., 2009), que há falhas de alta relevância no processo: por um lado, mesmo quando as bases expressam sua opinião, a maioria dos representantes atua segundo sua concepção pessoal e, por outro, mesmo sabendo por meio da prestação de contas dos representantes que sua orientação não foi seguida, essas bases os mantêm.

Embora os autores não tenham adentrado nessa discussão, esse paradoxo aparece subliminarmente e constitui aspecto a ser observado para o exercício do controle social. Trata-se, portanto, da necessidade de um controle efetivo sobre o voto do representante em um movimento de mão dupla, mas sem burocratização nem autoritarismo: reuniões frequentes com as bases para definir pautas de discussão e indicar soluções para os problemas envolvidos; relatórios de prestação de contas sobre sua atuação em cada reunião do fórum participativo e suspensão temporária ou até cassação de seu mandato caso, reiteradamente, não siga as orientações das bases.

Assim, pode-se buscar assegurar, como profilaxia e medida corretiva, que representantes, principalmente dos segmentos mais excluídos da 
sociedade, não sejam envolvidos em processos de manipulação, cooptação e outros por parte de segmentos mais poderosos (Arnstein, 1969).

Finalmente, sobre a influência externa das tomadas de decisão nos fóruns, os dados apresentados no único trabalho identificado que trata a respeito da questão (Abers et al., 2009), embora limitados, conforme os próprios autores ressaltam, revelam que o governo e suas políticas são mais sensíveis às deliberações dos fóruns participativos em comparação com o setor privado e a sociedade em geral.

Como propõe Gramsci, o Estado incorpora as demandas das classes subalternas com o fito de contemporizar e assegurar o status quo. Portanto, neste caso, investigar até que ponto essa incorporação se dá e que benefícios concretos se desenham a partir daí para as classes mais excluídas é algo merecedor de atenção em futuras investigações.

\section{Considerações finais}

Este estudo identificou a existência de diversos mecanismos de controle social, definidos pela PNRH no âmbito do Singreh como espaço participativo: órgãos colegiados como o CNRH, os CERH e os CBH. Contudo, também detectou a existência de entraves e limitações no funcionamento desses fóruns, tais como: interesses meramente comerciais e de acesso a recurso públicos; falta de qualificação da sociedade civil para participar em igualdade de condições com outros setores; risco de que, em função disso, a participação efetiva da sociedade seja limitada ou até anulada; dificuldades organizacionais, burocráticas, financeiras e decorrentes dos conflitos internos de opiniões, que comprometem inclusive a representatividade dos segmentos; baixo controle das bases sobre seus representantes e baixo impacto das deliberações sobre o Estado, o setor privado e a sociedade em geral.

Tal como na área de recursos hídricos, a de saneamento já dispõe, em seu marco legal, de mecanismos de participação, instituídos na perspectiva do controle social. Contudo, levando em conta os fatores limitantes supramencionados, pode-se afirmar que, se a existência da legislação é importante, não é suficiente. É importante, posto que organiza as relações entre os atores sociais envolvidos, definindo seus direitos e deveres; não é suficiente, pois não assegura que as práticas decorrentes sejam empreendidas de modo a concretizar os objetivos propostos.

Essa afirmativa se evidencia fortemente na área de saneamento, considerando-se suas matrizes históricas, marcadas pelo centralismo e o autoritarismo herdados do modelo de gestão estabelecido no período da ditadura militar. Nesse caso, a legislação define novas práticas - mais democráticas - que, contudo, esbarram na resistência e/ou na falta de experiência dos atores envolvidos.

Assim, por exemplo, são criados órgãos colegiados participantes da formulação e da condução da política de saneamento, atendendo à demanda legal, mas cuja atuação é tornada ineficaz por conta de sua natureza apenas consultiva. Se colegiados deliberativos como os de recursos hídricos enfrentam todas as dificuldades e limitações aqui expostas, certamente são mais acerbas as lutas enfrentadas pelos fóruns apenas consultivos.

Portanto, a grande lição que se pode extrair da experiência brasileira de gestão das águas, ainda mais em uma circunstância de escassez hídrica que impacta algumas regiões do país e que atinge mais severamente segmentos da população que estão à margem do poder político, social e econômico, é de que está em pauta o desafio de envidar esforços para a ampla capacitação dos agentes sociais.

Esse esforço deve abranger todos os agentes, mas principalmente os mais vulneráveis e excluídos, para que, organizados e capazes de dominar os códigos hegemônicos citados, possam superar as dificuldades existentes - inclusive, no caso do saneamento, a natureza não deliberativa dos órgãos colegiados - e interferir positivamente na gestão pública, orientando as ações e os gastos governamentais na direção dos interesses coletivos, neste caso, em defesa do acesso a um bem da maior importância: a água.

\section{Referências}

ABERS, R. N. et al. Inclusão, deliberação e controle: três dimensões de democracia nos comitês e consórcios de bacias hidrográficas no Brasil. Ambiente e Sociedade, São Paulo, v. 12, n. 1, p. 115-132, 2009. 
ARAÚJO, D. C.; RIBEIRO, M. M. R.; VIEIRA, Z. M. C. L. Conflitos institucionais na gestão dos recursos hídricos do estado da Paraíba. Revista Brasileira de Recursos Hídricos, Porto Alegre, v. 17, n. 4, p. 259-271, 2012.

ARNSTEIN, S. A. A ladder of citizen participation. Journal of the American Institute of Planners, London, v. 35, n. 4, p. 216-224, 1969.

BERRETA, M. S. R.; LAURENT, F.; BASSO, L. A. Os princípios e fundamentos da legislação das águas na França. Boletim Gaúcho de Geografia, Porto Alegre, v. 39, p. 13-24, 2012.

BOBBIO, N. Dicionário de Política. Brasília, DF: UnB, 1986.

BRAGA, L. M. M.; FERRÃO, A. M. A. A gestão dos recursos hídricos na França e no Brasil com foco nas bacias hidrográficas e seus sistemas territoriais. Labor \& Engenho, Campinas, v. 9, n. 4, p. 19-33, 2015.

BRASIL. Constituição da República Federativa do Brasil de 1988. Diário Oficial da União, Brasília, DF, 5 out. 1988.

BRASIL. Lei $n^{\circ}$ 9.433, de 8 de janeiro de 1997. Institui a Política Nacional de Recursos Hídricos, cria o Sistema Nacional de Gerenciamento de Recursos Hídricos, regulamenta o inciso XIX do art. 21 da Constituição Federal, e altera o art. $1^{\circ}$ da Lei $n^{0}$ 8.001, de 13 de março de 1990, que modificou a Lei $\mathrm{n}^{0} 7.990$, de 28 de dezembro de 1989. Diário Oficial da União, Brasília, DF, 9 jan. 1997. Disponível em: <http://bit.ly/1iC6rDg>. Acesso em: 27 out. 2017.

BRASIL. Lei $n^{\circ} 11.346$, de 15 de setembro de 2006 . Cria o Sistema Nacional de Segurança Alimentar e Nutricional - SISAN com vistas em assegurar o direito humano à alimentação adequada e dá outras providências. Diário Oficial da União, Brasília, DF, 18 set. 2006. Disponível em: <http:// bit.ly/1DuaUym>. Acesso em: 27 out. 2017.

BRAVO, M. I. S.; CORREIA, M. V. C. Desafios do controle social na atualidade. Serviço Social e Sociologia, São Paulo, n. 109, p. 126-15o, 2012. CAMPOS, V. N. O. Comitê de bacia hidrográfica: um canal aberto à participação e à política?
Revista de Gestão da Água na América Latina, Porto Alegre, v. 2, n. 2, p. 49-6o, 2005.

CARNOY, M. Estado e teoria política. Campinas: Papirus, 1988.

CASTRO, J. E. Water governance in the twentiethfirst century. Ambiente e Sociedade, São Paulo, v. 10, n. 2, p. 97-118, 2007.

CEPAL - COMISIÓN ECONÓMICA PARA AMÉRICA LATINA Y EL CARIBE. Recomendaciones de las reuniones internacionales sobre el agua: de Mar del Plata a Paris. Santiago: Cepal, 1998. Disponível em: <http://bit.ly/2iH2Htd >. Acesso em: 13 jul. 2015 .

CHIODI, R. E.; SARCINELLE, O.; UEZU, A. Gestão dos recursos hídricos na área do sistema produtor de água Cantareira: um olhar para o contexto rural. Revista Ambiente e Água, Taubaté, v. 8, n. 3, p. 151-165, 2013.

CORREIA, M. V. C. Desafios para o controle social: subsídios para capacitação de conselheiros de saúde. Rio de Janeiro: Fiocruz, 2005.

COUTINHO, C. N. Gramsci e sociedade civil. Gramsci e o Brasil, Juiz de Fora, 20oo. Disponível em: <http://bit.ly/2zdkLCy>. Acesso: 29 ago. 2017.

COUTINHO, C. N. O desafio dos que pensaram bem o Brasil. Lua Nova, São Paulo, n. 54, p. 103-113, 2001.

DOURADO JUNIOR, O. C. Gestão de recursos hídricos nos países da Bacia Amazônica: conflitos legislativos. 2011. Tese (Doutorado em Ciências - Desenvolvimento Socioambiental) - Núcleo de Altos Estudos Amazônicos, Universidade Federal do Pará, Belém, 2011. Disponível em: <http://bit. ly/2zUyY46>. Acesso em: 11 out. 2016.

EMPINOTTI, V. L. E se eu não quiser participar? O caso da não participação nas eleições do Comitê de Bacia do Rio São Francisco. Ambiente e Sociedade, São Paulo, v. 14, n. 1, p. 195-211, 2011.

FIGUEIRÊDO, M. C. B. et al. Monitoramento comunitário da qualidade da água: uma ferramenta para a gestão participativa dos recursos hídricos no semiárido. Revista de Gestão da Água na América Latina, Porto Alegre, v. 5, n. 1, p. 51-6o, 2008. 
FLORES, R. K.; MIZOCZKY, M. C. Participação no gerenciamento de bacia hidrográfica: o caso do Comitê Lago Guaíba. Revista de Administração Pública, Rio de Janeiro, v. 2, n. 1, p. 109-131, 2008.

HAASE, J. F.; GUTIÉRREZ, R. A. La reforma de la gestión del agua en el estado de Río Grande del Sur (Brasil), 1979-2006. Revista de Gestão da Água na América Latina, Porto Alegre, v. 5, n. 2, p. 53-69, 2008.

IAMAMOTO, M. V.; CARVALHO, R. Relações sociais e serviço social no Brasil: esboço de uma interpretação histórico-metodológica. São Paulo: Cortez: Celats, 1988.

IELA - INSTITUTO DE ESTUDOS LATINOAMERICANOS. A lei de águas no Equador tem armadilhas para privatizar a água. Iela, Florianópolis, 15 jan. 2015. Disponível em: <http:// bit.ly/2zbNDee>. Acesso em: 11 out. 2016.

JACOBI, P. R.; BARBI, F. Democracia e participação na gestão dos recursos hídricos no Brasil. Revista Katálysis, Florianópolis, v. 10, n. 2, p. 237-244, 2007. MACCIOCCHI, M. A. A favor de Gramsci. Rio de Janeiro: Paz e Terra, 1980.

MALHEIROS, T. F.; PROTA, M. G.; RINCÓN, M. A. P. Participação comunitária e implementação dos instrumentos de gestão da água em bacias hidrográficas. Revista Ambiente e Água, Taubaté, v. 8, n. 1, p. 99-118, 2013.

MARTINS, R. C. Fronteiras entre desigualdade e diferença na governança das águas. Ambiente e Sociedade, São Paulo, v. 18, n. 1, p. 221-238, 2015.

MELLO, M. C. C.; REZENDE, S. O Conselho Municipal de Saneamento de Belo Horizonte: desafios e possibilidades. Engenharia Sanitária e Ambiental, Rio de Janeiro, v. 19, n. 4, p. 479-488, 2014.

MORONI, J. A. O direito à participação no governo Lula. In: AVRITZER, L. (Org.). Experiências nacionais de participação social. São Paulo: Cortez, 2009. p. 107-141.

NOGUEIRA, E. Maior seca dos últimos 100 anos provoca mudanças no uso da água no Ceará. Agência Brasil, Brasília, DF, 2016. Disponível em: <http://bit.ly/2czEmD3>. Acesso em: 11 out. 2016.
ONU - ORGANIZAÇÃO DAS NAÇÕES UNIDAS.

Resolução A/RES/64/292, aprovada pela

Assembleia Geral das Nações Unidas em 28 de julho de 2010. Genebra, 2010. Disponível em: <http://bit.ly/1CcbtRm>. Acesso em: 26 nov. 2017.

PADILLA, J. H. R. et al. Análisis comparativo de modelos e instrumentos de gestión integrada del recurso hídrico en Suramérica: los casos de Brasil y Colombia. Revista Ambiente e Água, Taubaté, v. 8, n. 1, p. 73-97, 2013.

PIMENTEL, C. Seca na Amazônia pode bater recorde histórico em 2016. Agência Brasil, Brasília, DF, 2016. Disponível em: <http://bit. ly/2cnpRgz>. Acesso em: 11 out. 2016.

PITERMAN, A.; HELLER, L.; REZENDE, S. C. (A falta de) controle social das políticas municipais de saneamento: um estudo em quatro municípios de Minas Gerais. Saúde e Sociedade, São Paulo, v. 22, n. 4, p. 1180-1192, 2013.

PORTO, M. F. A.; PORTO, R. L. L. Gestão de bacias hidrográficas. Revista Estudos Avançados, São Paulo, v. 22, n. 63, p. 43-6o, 2008.

PROTA, M. G. Análise do processo participativo na gestão dos recursos hídricos no Estado de São Paulo: um estudo de caso do Comitê de Bacia Hidrográfica do Tietê-Jacaré. 2011. Dissertação (Mestrado em Saúde Pública) - Faculdade Saúde Pública, Universidade de São Paulo, São Paulo, 2011. Disponível em: <http://bit.ly/2iFCefM>. Acesso em: 11 out. 2016.

PUTNAM, R. D. Comunidade e democracia: a experiência da Itália moderna. Rio de Janeiro: FGV, 2002.

SANTIN, J. R.; GOELLNER, E. A gestão dos recursos hídricos e a cobrança pelo seu uso. Sequência, Florianópolis, v. 67, p. 199-221, 2013.

TUNDISI, J. G. Recursos hídricos no futuro: problemas e soluções. Estudos Avançados, São Paulo, v. 63, n. 22, p. 7-16, 2008.

ULLER-GÓMEZ, C.; SHEIBE, L. F.; REIS, M. J. Agricultores familiares e participação na gestão das águas na bacia do Itajaí/SC. Revista de Gestão da Água na América Latina, Porto Alegre, v. 5, n. 2, p. 39-51, 2008. 
VIEIRA, V. P. P. B. Sustentabilidade do semiárido brasileiro: desafios e perspectivas. Revista

Brasileira de Recursos Hídricos, Porto Alegre, v. 7, n. 4, p. 105-112, 2002.
WOLKMER, M. F.; PIMMEL, N. F. Política nacional de recursos hídricos: governança da água e cidadania ambiental. Sequência, Florianópolis, v. 67, p. 165-198, 2013. 